\title{
EFFECT OF DESIGN PARAMETERS ON ENERGY MITIGATION BY A DEBRIS FLOW BARRIER
}

\author{
MIN-SEOP KIM, SEUNG-RAE LEE, NIKHIL NEDUMPALLILE VASU \& JUN-SEO JEON \\ Korea Advanced Institute of Science and Technology, South Korea
}

\begin{abstract}
This paper presents debris mobility analysis results for a slit type debris flow barrier and the effect of its design parameters on the barrier's performance. Numerical simulation of various cases was performed using CFD program FLOW-3D with different heights and slit ratios of barrier. The result shows reasonably correlated relationships between the barrier's design parameters and energy mitigation by the barrier, which can contribute to an optimum design of the debris flow barrier.

Keywords: debris flow, multiphase simulation, debris flow barriers, slits.
\end{abstract}

\section{INTRODUCTION}

Debris flows, which flow with extremely rapid velocity and large volume, can cause economic and societal damages in urban areas. One of the methods to prevent this flow is to install debris flow barrier that blocks the mass and dissipates energy of the flow [1]. Many researchers investigated the mechanism involved in the debris flow barrier based on experiments [2]-[4] and by numerical studies [5]-[7]. Wenbing and Guoqiang [2] performed non-viscous debris flow experiment and examined the effect of slit size on debris flow trapping. Lim et al. [3] compared the trap effect of various slit type barriers with hydraulic model experiment. Choi and Kwon [4] investigated the role of spacing and angle of slit-type barriers on velocity reduction and trap ratio of debris flows in laboratory-scaled experiment. Kwan et al. [5] propose a staged debris flow with effect of multiple debris flow barrier and compare the results with numerical simulations. Armanini and Larcher [6] theorized and experimented debris flow barrier with single slit in a narrow basin and suggested a rational criterion for the design of barrier to control the bed/suspended load and its deposition. Campisano et al. [7] improved the evaluation of [6] by considering unsteady flow conditions to decrease inaccuracies of hypothesis of [6].

However, performance of slit type barrier against debris flows with respect to other design parameters still remains poorly identified. Moreover, many of researchers did not consider the effect of overflow when the debris flow first hit the barrier, which greatly influences the energy mitigation and trapping performance.

In this paper, energy mitigation and trap ratio for different types of barrier were obtained with variation of height and slit ratio. Numerical flow simulations were conducted for this study via a sediment-scour physics model implemented in a CFD program FLOW-3D which considers transport of both solid and liquid phases of debris flow. Reliability of the simulations with FLOW-3D was also checked by comparing the numerical solution with the results of Choi and Kwon [4].

\section{NUMERICAL MODEL}

\subsection{Flow-3D}

Flow-3D is a commercially available CFD software that can simulate many flow processes and it is capable of predicting the free-surface flows with high accuracy. The algorithm is 
based on Volume of Fluid (VOF) method which was first developed by Hirt and Nichols [8]. The sediment scour model calculates the sediment transport processes including entrainment, deposition, bedload transport and suspended load transport by using empirical models for each process [9]. The velocity at which the grains leave the packed bed and settling velocity are calculated based on eqn (1) and eqn (2) respectively.

$$
\begin{gathered}
u_{\text {lift } . i}=\alpha_{i} \boldsymbol{n}_{\boldsymbol{b}} d_{*}^{0.3}\left(\theta_{i}-\theta_{c r, i}\right)^{1.5} \sqrt{\frac{\|g\| d_{i}\left(\rho_{i}-\rho_{f}\right)}{\rho_{f}}}, \\
u_{\text {settling }, i}=\frac{v_{f}}{d_{i}}\left[\left(10.36^{2}-1.049 d_{*}^{3}\right)^{0.5}-10.36\right],
\end{gathered}
$$

where $\alpha_{i}$ is the entrainment coefficient of species $i, n_{b}$ is the outward normal vector of the packed bed surface, $\theta_{i}$ is a shields parameter, $\theta_{c r, i}$ is a critical shields parameter, $d_{i}$ is grain diameter, $\rho_{i}$ is the mass density of sediment grains, $\rho_{f}$ is mass density of fluid and $v_{f}$ is the kinetic viscosity of fluid. $d_{*}$ is the dimensionless grain size given by eqn (3).

$$
d_{*}=d_{i}\left[\frac{g\left(\rho_{i} / \rho_{f}-1\right)}{v_{f}{ }^{2}}\right]^{1 / 3}
$$

Bed-load transport is the model of sediment transport due to rolling or bouncing over the surface of the packed bed of sediment and FLOW-3D provides three different equations for volumetric bedload transport rate of sediment $q_{i}$. In this study, Meyer-Peter and Muller equation was selected for bedload transport calculation (eqn 4).

$$
q_{i}=c_{i} B_{i}\left[g\left(\rho_{i} / \rho_{f}-1\right) d_{i}^{3}\right]^{0.5}\left(\theta_{i}-\theta_{c r, i}\right)^{1.5},
$$

where $c_{i}$ is the volume fraction of species $i$ in the bed material and $B_{i}$ is the bedload coefficient.

Suspended load transport is calculated by solving its own transport eqn (5).

$$
\frac{\partial C_{s, i}}{\partial \mathrm{t}}+\nabla \cdot\left(u_{i} C_{s, i}\right)=\nabla \cdot \nabla\left(D C_{s, i}\right)
$$

where $C_{s, i}$ is suspended sediment volume concentration, $u_{i}$ is sediment velocity, and $D$ is the diffusivity.

\subsection{Model in simulation}

Channel for debris flow is simply modelled as shown in Fig. 1. Width and length of the modelled channel is $0.1 \mathrm{~m}$ and $1.6 \mathrm{~m}$, respectively and barriers were located in the middle of channel. To investigate the effect of height and slit ratio on energy mitigation, 30 cases were simulated with 6 different heights $H(20 \mathrm{~mm}, 40 \mathrm{~mm}, 70 \mathrm{~mm}, 90 \mathrm{~mm}, 110 \mathrm{~mm}, 130 \mathrm{~mm})$ and 5 slit ratios $r=\frac{b}{B}(0,0.1,0.15,0.2)$ (Fig. 2). Main properties of sediment used in the threedimensional model is listed in Table 1.

\section{RESULTS}

\subsection{Energy mitigation}

Imaginary plane (Plane A) located $0.7 \mathrm{~m}$ from barriers was created to get the kinetic flow energy. Then the energy distribution of each case was plotted in Fig. 3 and data sets with same slit ratio was group in same colours. In the case of closed barrier, kinetic flow energy decreases with increases of height. Slit-type debris flow barrier also exhibits a negative relationship with height of the barrier in general but its change is less influenced by the height change. However, the kinetic flow energy shows a positive relationship with the slit ratio. 
Figs 4 and 5 show the variation of kinetic energy with change of impacted area of barrier. Data sets that have same slit ratio (Fig. 4) and height (Fig. 5) were expressed in same colours. Average inclination shown in Fig. 4 is steeper than that shown in Fig. 5 and it can be concluded that change of slit ratio influences more on the energy mitigation than change of height.

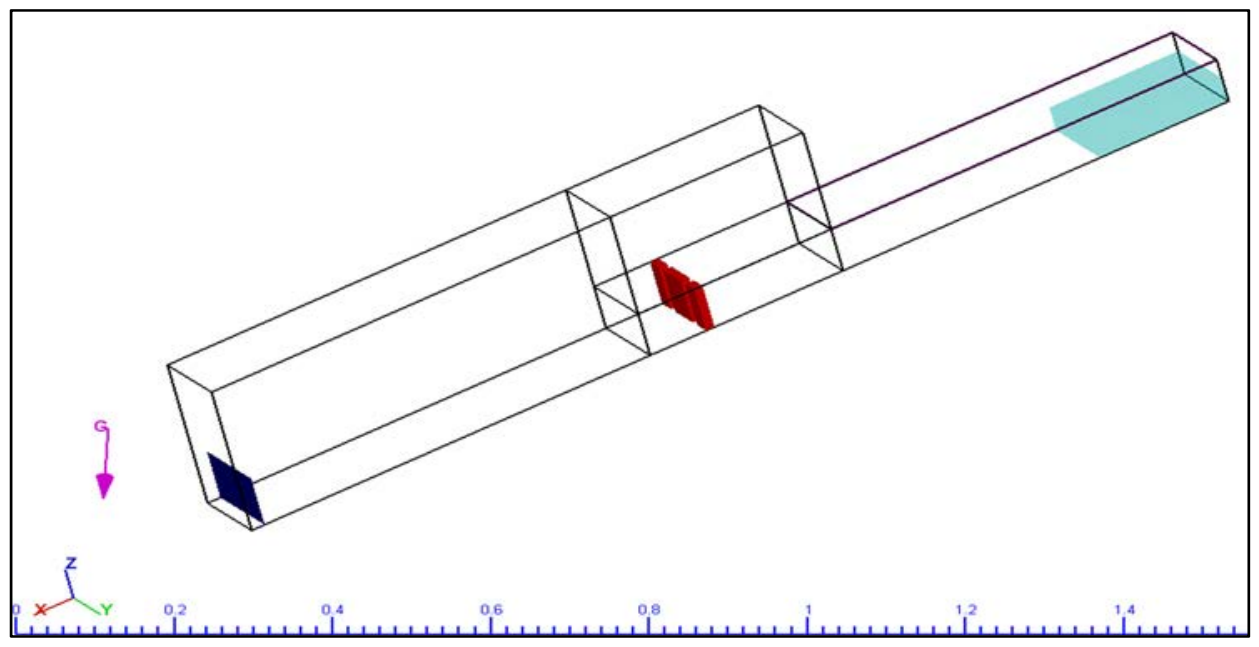

Figure 1: Three-dimensional model for debris flow channel.

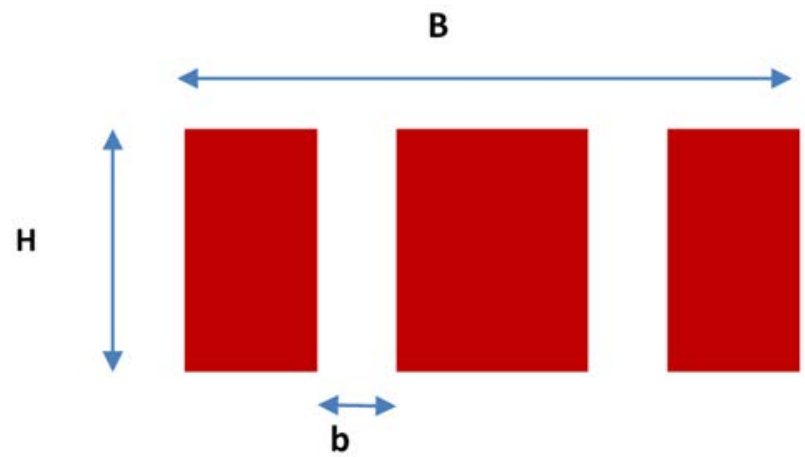

Figure 2: Design of barrier in the model.

Table 1: Input properties of sediment in three-dimensional model.

\begin{tabular}{cccccc}
\hline Item & Unit & Value & Item & Unit & Value \\
\hline Initial Volume & $\mathrm{m}^{3}$ & 0.001 & Grain Density & $\mathrm{kg} / \mathrm{m}^{3}$ & 2650 \\
Density & $\mathrm{kg} / \mathrm{m}^{3}$ & 1160 & Grain Mean Diameter & $\mathrm{mm}$ & 0.6 \\
Critical Shields Number & 1 & 0.05 & Bed Load Coefficient & 1 & 8 \\
Entrainment Coefficient & 1 & 0.018 & Angle of Repose & Degree & 32 \\
\hline \hline
\end{tabular}


22 Computational and Experimental Methods in Multiphase and Complex Flow IX

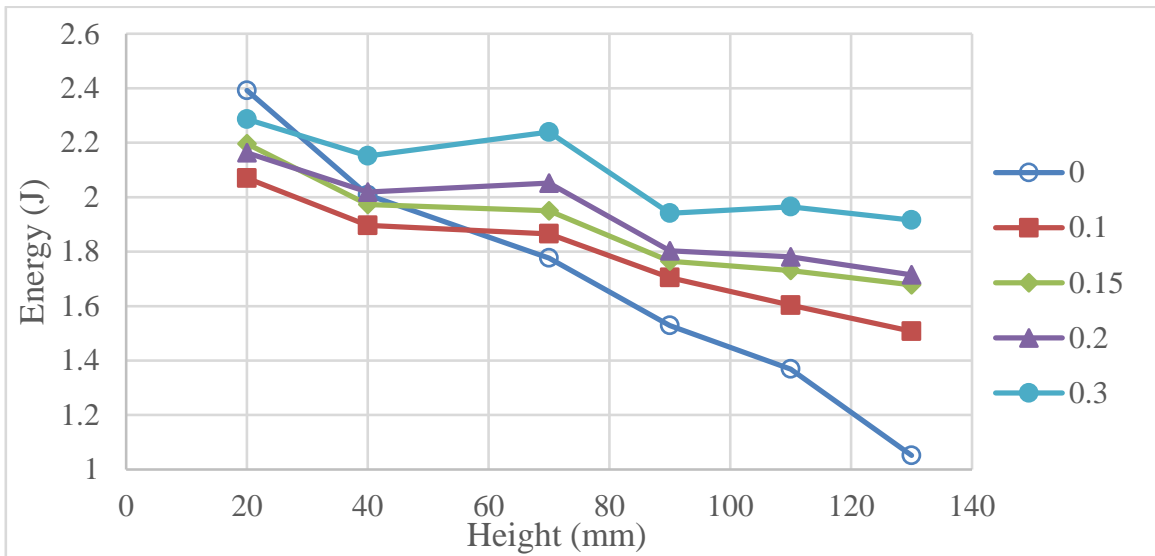

Figure 3: Distribution of debris flow energy with height/slit ratio change.

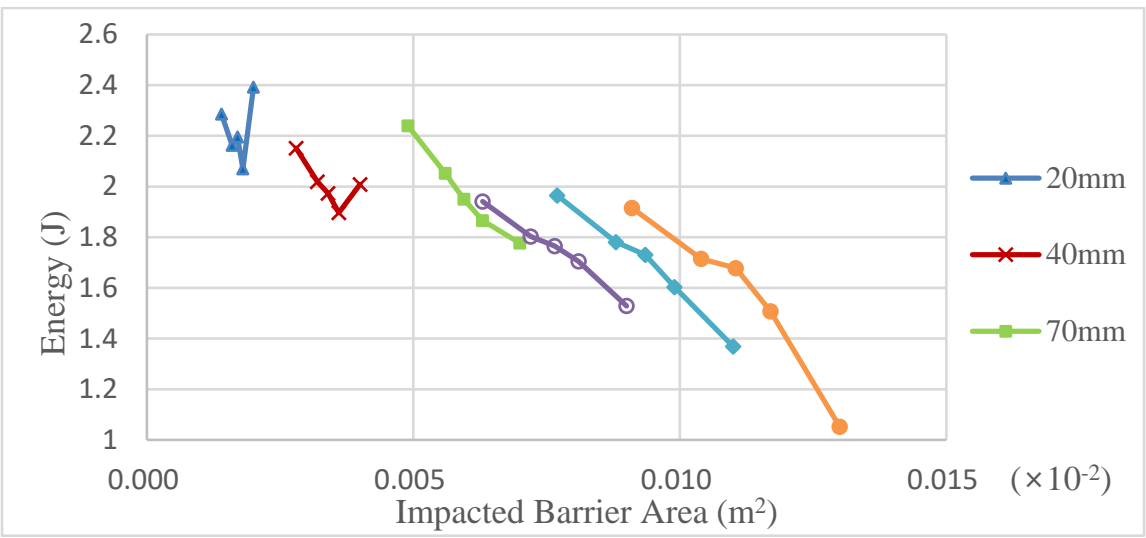

Figure 4: Distribution of debris flow energy with impacted barrier area (slit ratio change).

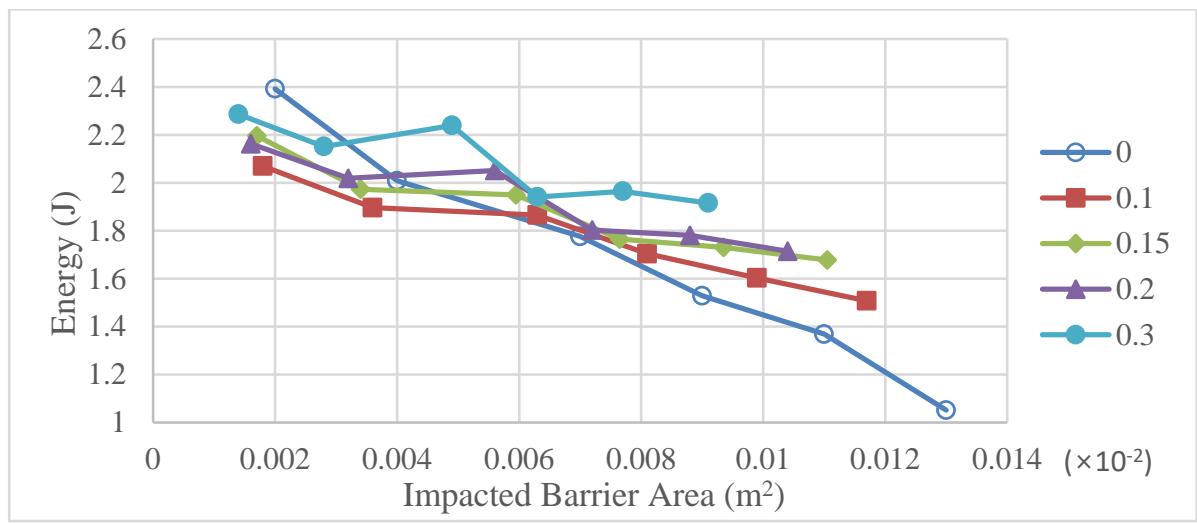

Figure 5: Distribution of debris flow energy with impacted barrier area (height change). 


\subsection{Trap effect}

Fig. 6 plots trap ratios of packed sediment that deposited behind barriers. Trap efficiency can be calculated with an initial sediment mass of $1.043 \mathrm{~kg}$. The result shows that in all the open type barrier cases, the trap ratio increases drastically when the height of barrier changes from $70 \mathrm{~mm}$ to $90 \mathrm{~mm}$. If the barrier height is less than $70 \mathrm{~mm}$, sediment deposited like Fig. 7 while sediment deposited on wider area like Fig. 8(a). Fig. 8(b) shows that change of deposited sediment volume with time is different between two groups.

Moreover, some effect of trapping decreases when the barrier height increases from $90 \mathrm{~mm}$ to $110 \mathrm{~mm}$. Therefore, it seems that there must be a threshold and optimum value in the dimension of barrier to collect an effective trapped material.

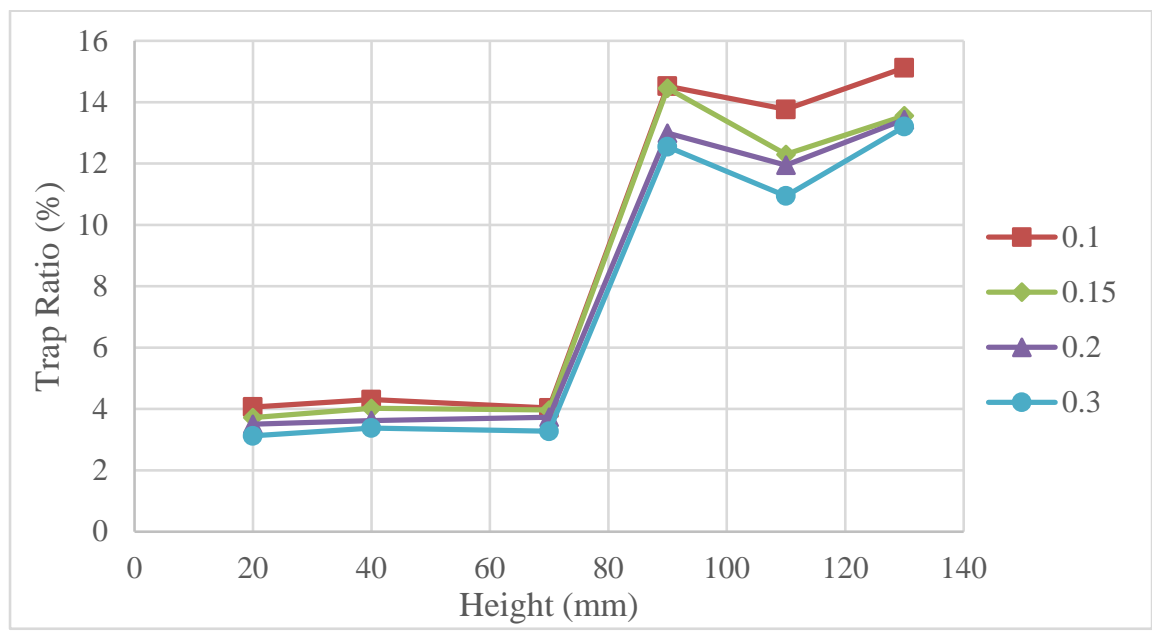

Figure 6: Distribution of trap ratio with change of design.

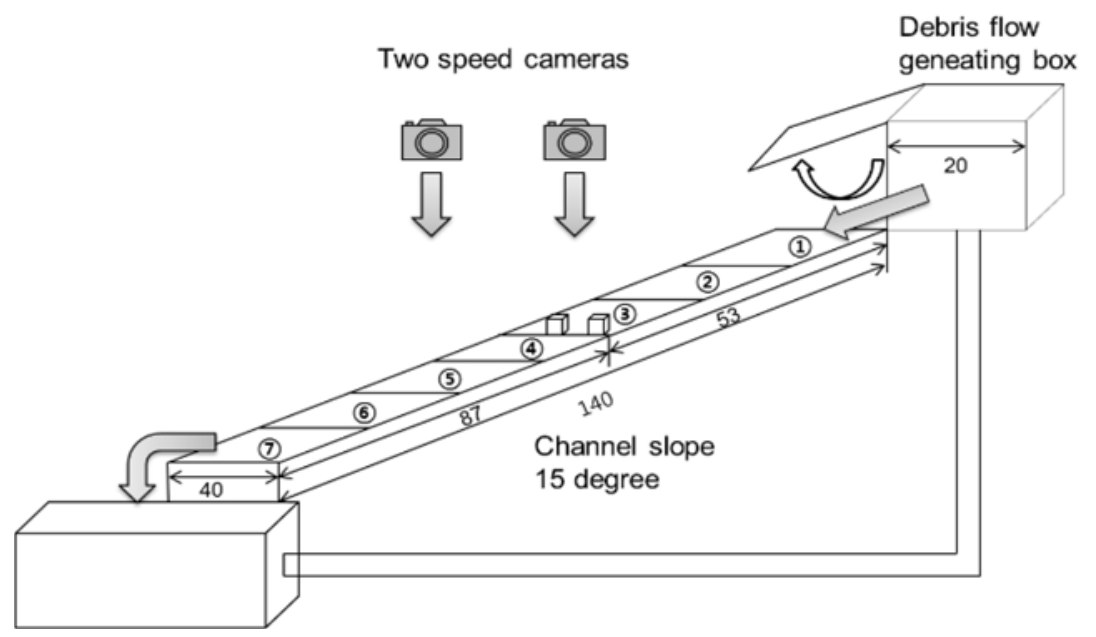

Figure 7: A schematic drawing of the experimental setup [4]. 

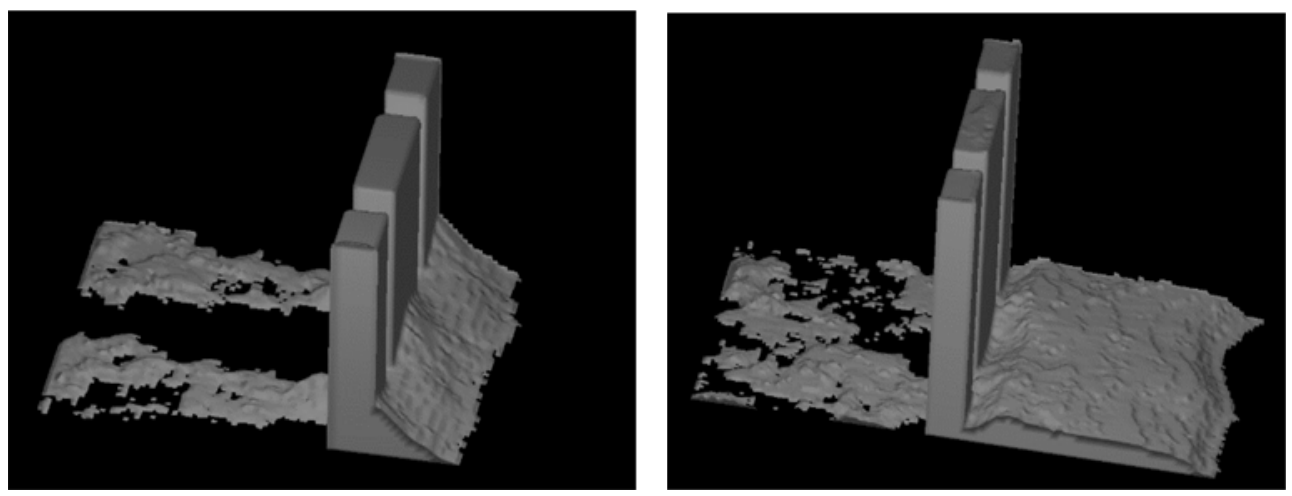

Figure 8: (a) Sediment deposition (height =70mm); (b) Sediment deposition (height $=90 \mathrm{~mm}$ )

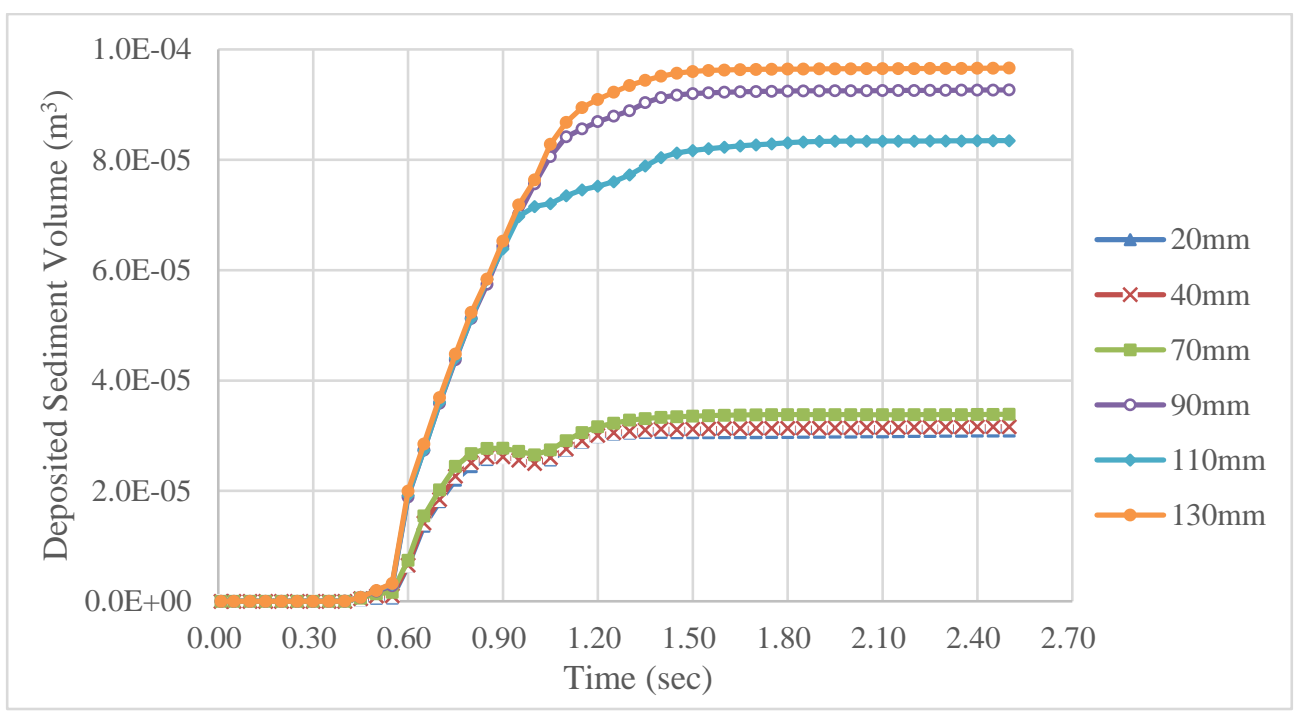

Figure 9: Deposited sediment volume change with time.

\section{NUMERICAL VALIDATION}

Choi and Kwon [4] performed laboratory-scaled experiment of slit-type barriers and analysed the roles of barrier arrangement on velocity reduction and trap ratio in debris flows. To check the reliability of the program, simulation that has same conditions with experiment of Choi and Kwon [4] was performed and the numerical solution was compared with experiment data.

\subsection{Experimental condition}

Choi and Kwon [4] used a mixture with $3.5 \mathrm{~kg}$ of water and $1 \mathrm{~kg}$ of Joomunjin standard sand (mean diameter $0.6 \mathrm{~mm}$ ) for debris flow generation. Schematic concept of experimental setup is shown in Fig. 7. Experiment was scaled down to 1/30 from an average barrier size in Korea so that scaled width, length of channel and width of barriers are $0.4 \mathrm{~m}, 1.4 \mathrm{~m}$ and $50 \mathrm{~mm}$ 
respectively. The barrier is located between section 3 and section 4 of channel and in order to consider the arrangement effect of barriers, 7 types of barrier with different angle of barriers (Fig. 10) were tested. To measure velocity data of debris flow, two speed cameras captured the speed of test particle and the pictures were analysed using particle tracking velocimetry program.

\subsection{Comparison with numerical solution}

Comparison between numerical solution and experimental data of flow velocity in section 5 is shown in Fig. 11. General trend of reduction ratio match well with the experiment. Besides, it supports conclusion of Choi and Kwon [4] that V type barrier arrangement shows higher velocity reduction than $\mathrm{P}$ type barriers. Error between numerical solution and experimental data considered to be induced by difference in method of measuring the debris flow velocity.

\section{CONCLUSION}

This study investigated the influence of design parameters (height and slit ratio) for a debris flow barrier based on the numerical flow simulation results. The performance of a barrier can be evaluated with kinetic flow energy and trap ratio for each case.

The distribution of energy in accordance with impacted barrier area was considered and it could be concluded that change of slit ratio influences more on energy mitigation than change
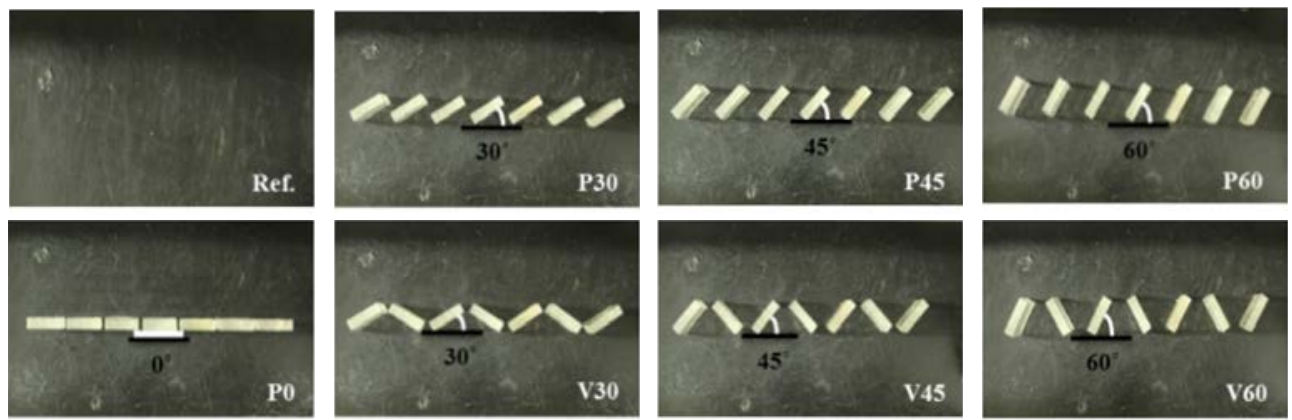

Figure 10: Arrangement of slit-type barriers [4].

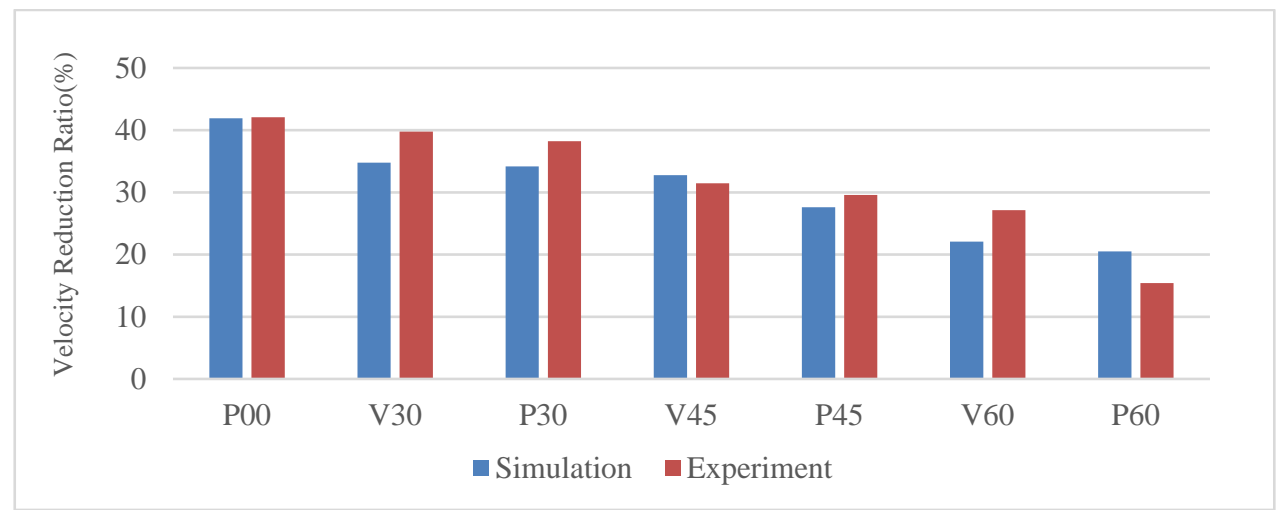

Figure 11: Velocity reduction ratio in section 5. 
of height. As for the trap ratio, it seems that there might be sudden increase when the barrier height exceeds a threshold value. If the height is lower than the threshold value, most of the debris flows through the slits or over the barrier and the barrier is not capable of slowing down the flow to the settling velocity. It implies that a specific value of barrier height that greatly increases the trapping performance and energy mitigation should be considered in design of debris flow barrier.

\section{ACKNOWLEDGEMENT}

This study was supported by the National Research Foundation of Korea under the Ministry of Education, Science and Technology (under grant no. 2013M3A2A1054838), and Ministry of Land, Transport and Maritime Affairs (MLTM) as part of the U-City Master and Doctor Course Grant program.

\section{REFERENCES}

[1] Zollinger, F., Debris detention basins in the European Alps. In Proc. Int. Symp. Erosion, debris flow and disaster prevention, Tsukuba, Japan, 11(4), pp. 433-438, 1985.

[2] Wenbing, H. \& Guoqiang, O., Efficiency of slit dam prevention against non-viscous debris flow. Wuhan University Journal of Natural Sciences, 11(4), pp. 865-869, 2006.

[3] Lim, Y.H., Jeon, G.U., Kim, M.S., Yeom G.J. \& Lee, J.H., Capture effect of slit dam for debris flow and woody debris with hydraulic model experiment - Focusing on A and D type. Summer conference of Korean Forest Society, pp. 343-344, 2008.

[4] Choi, S.K. \& Kwon, T.H., Roles of spacing and angle of slit-type barriers on velocity reduction of debris flows. Japanese Geotechnical Society Special Publication, 2(26), pp. 963-966, 2016.

[5] Kwan, J.S.H., Koo, R.C.H. \& Ng, C.W.W., Landslide mobility analysis for design of multiple debris-resisting barriers. Canadian Geotechnical Journal, 52(9), pp. 13451359, 2015.

[6] Armanini, A. \& Larcher, M., Rational criterion for designing opening of slit-check dam. Journal of Hydraulic Engineering, 127(2), pp. 94-104, 2001.

[7] Campisano, A., Cutore, P. \& Modica, C., Improving the evaluation of slit-check dam trapping efficiency by using a 1D unsteady flow numerical model. Journal of Hydraulic Engineering, 2014. 140.7: 04014024.

[8] Hirt, C.W. \& Nichols, B.D., Volume of fluid (VOF) method for the dynamics of free boundaries. Journal of computational physics, 39(1), pp. 201-225, 1981.

[9] Wei, G., James Brethour, M.G. \& Burnham, J., Sedimentation scour model. Flow Science Report, pp. 3-14, 2014. 